\title{
Effect of metal ions on the stability of metallothionein in the degradation by cellular fractions in vitro
}

\author{
Si Houn Hahn', Ook Joon Yoo ${ }^{2}$ and \\ William A. Gahl ${ }^{3}$ \\ ${ }^{1}$ Department of Pediatrics, Ajou University School of Medicine, \\ Suwon 441-749, Korea \\ ${ }^{2}$ Department of Biological Science/Biomedical Center, Korea \\ Advanced Institute of Science and Technology, Taejon, Korea \\ ${ }^{3}$ Heritable Disorders Branch, National Institute of Child Health and \\ Human Development, National Institutes of Health, Bethesda, \\ Maryland, U.S.A. \\ ${ }^{1}$ Corresponding author: Tel, +82-31-219-5166; \\ Fax, +82-31-219-5166; E-mail, omik@madang.ajou.ac.kr
}

Accepted 22 March, 2000

Abbreviations: MT, Metallothionein

\begin{abstract}
Metallothioneins (MT), small molecular weight metal binding proteins are known to play an important protective role against heavy metal toxicity, either as antioxidants or pre-oxidants. However, the mode of metabolic fate of MTs in various metal complexes is not clearly understood. This study was carried out to better understand the mode of selective turnover rate of various form of MT in complexes with different metals. The degradation of in vitro translated mouse ${ }^{35} \mathrm{~S}$-cysteine-MT was examined in lysosomal or cytosolic fractions from mouse liver by gel electrophoresis and autoradiography. Overnight incubations of MT showed extensive proteolysis in the lysosomal fraction but not in cytosolic fractions. However, $\mathrm{Cu}^{2+}-\mathrm{MT}$ was found to be stable under the same experimental condition. In contrast, $\mathrm{Zn}$ did not interfere with MT degradation. These results suggest that lysosomes are chiefly responsible for MT removal and appears to be selective on the metals involved in the MT complex. In vitro, translated, radiolabeled MT provides a suitable substrate for investigating the characteristics of MT degradation.
\end{abstract}

Keywords: metallothionein, lysosome, degradation, copper, zinc

\section{Introduction}

Metallothioneins (MT) are a group of cysteine-rich low molecular weight (approximately 6000 to $7000 \mathrm{D}$ ) intracellular proteins that avidly bind heavy metals. Isoforms include MT-I, MT-II and MT-III, with similar molecular weights but slightly different amino acid compositions. Since MTs are inducible by cadmium (Cd), zinc (Zn), copper $(\mathrm{Cu})$, and dexamethasone, they are considered to play an important protective role against heavy metal toxicity (Hamer, 1985). Zn-MT appears to serve as an antioxidant, and Cu-MT has been shown to enhance lipid peroxidation in vitro (Stephenson et al., 1994). Depending upon its associated heavy metals, MT acts either as an antioxidant or pre-oxidant, although the mechanism remains unclear. Recent studies using MTI and MT-II knockout mice have also demonstrated that MT-I and MT-II help protect against $\mathrm{Cd}$ and $\mathrm{Zn}$ toxicities (Michalska et al., 1993; Liu et al., 1996a; Liu et al., 1996b; Kondo et al., 1997; Klaassen et al., 1998), while their protective roles against copper are still debated (Danks, 1995).

Recently, the potential toxicity of Cu-MT was evaluated in the toxic milk $(t x)$ mouse, a model for Wilson disease. In this murine model, MT was present in the nuclei of liver cells along with increased numbers of apoptotic cells (Xi Deng et al., 1998). Abnormally high levels of $\mathrm{MT}$ and $\mathrm{Cu}$ accompanied striking morphologic abnormalities in the livers of $t x$ mice. The presence of high amounts of copper-MT, and of copper in the nucleus, could be genotoxic and lead to an enhanced apoptosis. However, the exact mechanism of liver toxicity in the $t x$ mouse is not well understood.

Despite of considerable advances in understanding the physiochemical properties of MT, the mechanism of the MT cellular degradation still remained unresolved. Most of the studies on metabolism of MT have used in vivo pulse-labeling method either using labeled-divalent metals or sulfur labeled amino acids either cysteine and/or methionine. The half-lives of MT-I and MT-II in the liver cytosol of $\mathrm{Cu}^{2+}$ injected rats were only $15.4 \pm 1.5$ and $18.2 \pm 1.1 \mathrm{~h}$, respectively, but in in vitro studies of copper-metallothionein in the rat liver, no significant degradation of the Cu-MT complex was observed (Mehra et al., 1985).

In order to better understand a possible mode of cellular turnover rate of MT in various state of metal complexes, we have prepared radiolableled mouse MT by translation in in vitro reticulocyte lysate system and used it in the proteolysis experiments containing various mouse liver cellular fractions. Using this method, we demonstrated that degradation of MT occurs in the lysosome and that copper interferes with the degradation of MT while $\mathrm{Zn}$ showed no effect. 


\section{Materials and Methods}

\section{Preparation of labeled MT}

Radiolabeled mouse MT was prepared using the TnT coupled reticulocyte lysate system, as described by the manufacturer (Promega, WI, USA), and ${ }^{35}$ S-cysteine (specific activity, $980 \mathrm{Ci} / \mathrm{mmol}$; Amersham, Buckinghamshire, England). Mouse MT cDNA was kindly provided by Dr. Dean Hamer at the National Institutes of Health in Bethesda, MD, USA $1.5 \mu \mathrm{l}$ of synthesized ${ }^{35}$ S-cysteine labeled MT was diluted in $30 \mu \mathrm{l}$ of $0.05 \mathrm{M}$ sodium acetate $\mathrm{pH} 5.0$ containing $2.5 \mathrm{mM}$ 2-mercaptoethanol or $100 \mathrm{mM}$ Tris $\mathrm{pH} 7.4$, containing $100 \mathrm{mM} \mathrm{CaCl}_{2} .5 \mu \mathrm{l}$ of mixture was used to calculate the radioactivity after TCA precipitation.

\section{Isolation of mouse liver lysosomal and cytosolic fractions}

Mouse liver lysosomal and cytosolic fractions were prepared by the method of Regab et al. The final pellet, obtained from $40-50 \mathrm{~g}$ of liver, was suspended in $1 \mathrm{ml}$ of $0.02 \mathrm{M}$ citrate buffer, $\mathrm{pH} 4.8$, containing $0.2 \%(\mathrm{w} / \mathrm{v})$ Triton $\mathrm{X}-100$ and $0.02 \mathrm{M}$ 2-mercaptoethanol, freeze-thawed five times, and then centrifuged at $100,000 \mathrm{~g}$ for $1 \mathrm{~h}$. The supernatant fraction was stored in aliquots at $-20^{\circ} \mathrm{C}$. The cytosolic fraction was suspended in $100 \mathrm{mM}$ Tris $\mathrm{pH}$ 7.4, containing $100 \mathrm{mM} \mathrm{CaCl}_{2}$ and stored at $-20^{\circ} \mathrm{C}$.

\section{In vitro proteolysis of ${ }^{35} \mathrm{~S}$-labeled MT by lysosomal extracts and cytosolic extracts}

${ }^{35} \mathrm{~S}$-labeled MT $(5 \mu \mathrm{l})$ in sodium acetate buffer was incubated with $7 \mu \mathrm{l}(10 \mu \mathrm{g})$ of mouse liver lysosomal extract as described with minor modifications (Mehra et al., 1985). After incubation for $1-12 \mathrm{~h}$ at $37^{\circ} \mathrm{C}$, the reaction was stopped by freezing, treated with iodoacetic acid at neutral $\mathrm{pH}$, and followed by electrophoresis on $20 \%$ SDS polyacrylamide gels as described (Hahn et al., 1994; Hahn et el., 1995). The gel was dried, exposed to X-ray film at $-70^{\circ} \mathrm{C}$ and autoradiographed. $5 \mu$ of ${ }^{35} \mathrm{~S}$ labeled MT was incubated with $7 \mu \mathrm{l}(20 \mu \mathrm{g})$ of mouse liver cytosol containing Tris buffer, $\mathrm{pH}$ 7.4. Proteolysis of MT was stopped by freezing, followed by gel electrophoresis. The gel was dried, exposed to X-ray film at $-70^{\circ} \mathrm{C}$ and autoradiographed. ${ }^{35} \mathrm{~S}$-labeled MT was also incubated with trypsin in Tris buffer, followed by electrophoresis and autoradiography. The control contained ${ }^{35} \mathrm{~S}$ labeled MT and buffer without lysosomal or cytosolic fractions.

\section{In vitro proteolysis of ${ }^{35} \mathrm{~S}$-labeled MT by lysosomal} extracts in the presence of copper or zinc

Copper sulfate and zinc sulfate $(1$ and $10 \mu \mathrm{M})$ were added to the ${ }^{35} \mathrm{~S}$-labeled MT prior to incubating with lysosomal extracts for $12 \mathrm{~h}$. The reaction was stopped as above, electrophoresed, and autoradiographed.

\section{Results and Discussion}

\section{In vitro proteolysis of ${ }^{35} \mathrm{~S}$-labeled MT by lysosomal and cytosolic fractions}

${ }^{35} \mathrm{~S}$-labeled MT was degraded completely by lysosomal fractions of mouse liver, but not by cytosolic fractions when incubated overnight (Figure 1). Control buffer without either lysosomal or cytosolic fractions did not show any effect on the stability of the ${ }^{35} \mathrm{~S}$-labeled MT. When ${ }^{35} \mathrm{~S}$ labeled MT was incubated with cytosolic fractions, its molecular weight was slightly increased, with smearing of the band. When ${ }^{35} \mathrm{~S}$-labeled MT was adjusted to $\mathrm{pH} 7.4$ in the buffer without cytosolic extracts, the same smearing pattern appeared with increased molecular weight band suggesting a possible conformational change due to $\mathrm{pH} .{ }^{35} \mathrm{~S}$-labeled MT was shown to be sensitive to proteases in the neutral $\mathrm{pH}$ as demonstrated by the complete digestion with trypsin. This study demonstrates that MT is readily degraded by mouse liver lysosome at slight acidic environment, but not by neutral cytosolic fractions.

Although we have used equivalent levels of cellular fractions to simulate the in vivo cell state, it may still created the instability of neutral proteases during overnight incubation period in comparison with compartmentalized lysosomal enzymes. Since lysosomes are known to function as cellular clearing house, it is not surprising to find that MT degradation occurs mainly in this fraction. Whether there is a specific MT-degrading enzyme in the lysosome is not known yet. However, the in vitro technique we describe for assaying MT proteolysis can be employed to purify this putative enzyme(s).

In vitro proteolysis of ${ }^{35} \mathrm{~S}$-labeled MT by Iysosomal extracts in the presence of copper or zinc

When copper was added to the reaction, ${ }^{35} \mathrm{~S}$-labeled MT was not digested by the lysosomal extracts, while the

$\begin{array}{llllllllll}1 & 2 & 3 & 4 & 5 & 6 & 7 & 8 & 9 & 10\end{array}$

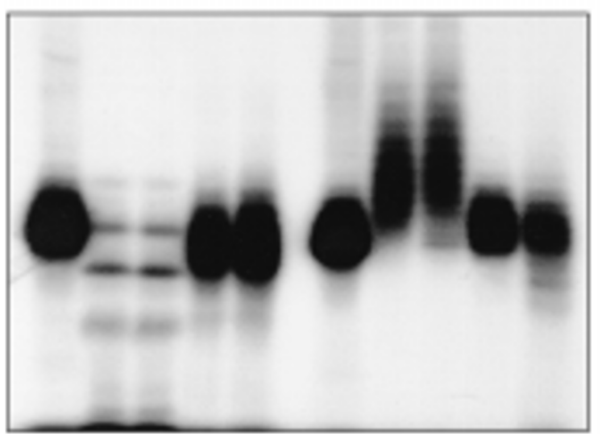

Figure 1. In vitro digestion of ${ }^{35} \mathrm{~S}$-labeled mouse-MT by lysosomal and cytosolic fractions. Lane 1: MT control, Lane 2, 3: MT incubated with lysosomal extracts, Lane 4, 5: MT in citrate buffer, Lane 6: MT control, Lane 7, 8: MT incubated with cytosolic extracts, Lane 9, 10: MT in Tris buffer, Lane 11, 12; MT incubated with trypsin. The proteins were incubated overnight, loaded on a $20 \%$ SDS-PAGE gel, dried and autoradiographed. 


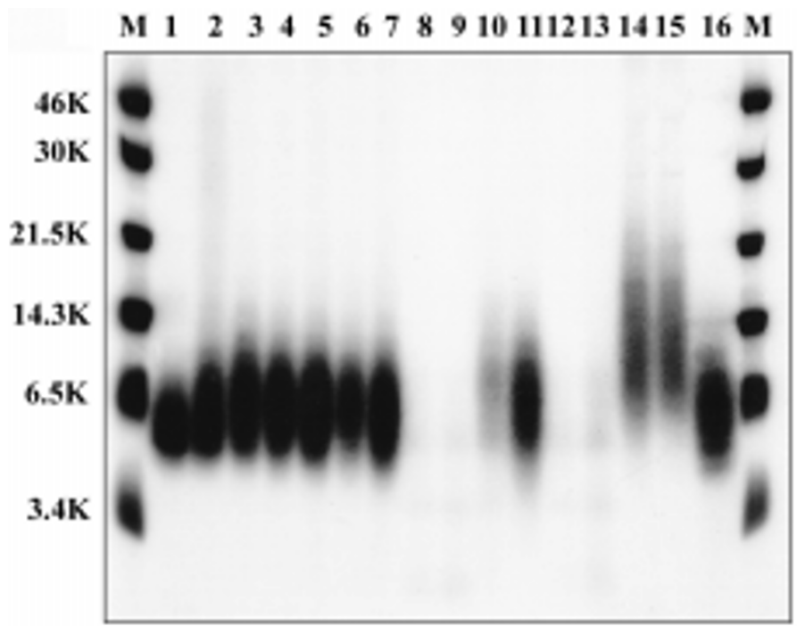

Figure 2. In vitro digestion of ${ }^{35} \mathrm{~S}$-labeled mouse-MT by lysosomal extracts in the presence of copper or zinc. M: Marker, Lane 1: MT control, Lane 2, 3: MT incubated with lysosomal extracts for 1h; Lane 4, 5: MT incubated with lysosomal extracts for $2 \mathrm{~h}$; Lane 6, 7: MT incubated with lysosomal extracts for $3 \mathrm{~h}$; Lane 8, 9: MT incubated with lysosomal extracts overnight; Lane 10: MT incubated with lysosomal extracts and $1 \mu \mathrm{M}$ copper overnight; Lane 11: MT incubated with lysosomal extracts and $10 \mu \mathrm{M}$ copper overnight; Lane 12: MT incubated with lysosomal extracts and $1 \mu \mathrm{M}$ Zn overnight; Lane 13: MT incubated with lysosomal extracts and $10 \mu \mathrm{M}$ Zn overnight; Lanes 14, 15: MT in Tris buffer pH 7.4, overnight incubation; Lane 16: MT control overnight incubation without buffer.

zinc did not interfere with the complete digestion of ${ }^{35} \mathrm{~S}$ labeled MT (Figure 2). The difference may not be contributed by the level of metal ion complexed with MT (binding capacity of MT toward copper or zinc) but more likely due to the oxidative and reductive transition state of each metals. Excess copper is very toxic and damages lipids, proteins and nucleic acids. Exposure of DNA to $\mathrm{H}_{2} \mathrm{O}_{2}$ in the presence of $\mathrm{Cu}$ salts can result in DNA strand breaks and base modification in vitro (Kawanishi et al., 1991; Marshall et al., 1981; Que et al., 1980). $\mathrm{Cu}(\mathrm{I})$ in the presence of $\mathrm{H}_{2} \mathrm{O}_{2}$ preferentially generates $\mathrm{Cu}$-peroxide complexes leading to production of singlet $\mathrm{O}_{2}$ and/or hydroxyl radicals $(\cdot \mathrm{OH})$, whereas $\mathrm{Cu}(\mathrm{II})$ in the presence of $\mathrm{H}_{2} \mathrm{O}_{2}$ generally forms $\cdot \mathrm{OH}$ by a Fenton reaction. These reactive oxygen species are capable of damaging critical cellular molecules.

The major hepatic copper binding protein both in Wilson's disease and its animal model, the toxic milk mouse, has been identified as metallothionein (MT). MTs are a group of low molecular weight (approximately 6000 D), cysteine rich proteins with high affinity for heavy metals such as Zn, Cd and Cu. MT combines with 11 or 12 copper ions, 5 or 6 bound to the amino terminal portion and another 5 or 6 to the carboxyl terminal. In the toxic milk mouse liver, accumulation of high levels of MT and $\mathrm{Cu}$ along with striking morphologic abnormalities have been observed. MT was also present in the nucleus along with increased numbers of apoptotic cells (Deng et al., 1999). MT appears to be involved in protection against apoptotic changes (Deng et al., 1999; Cabre et al., 1999; Tsangaris et al., 1998). MT associated with Cd has been shown to promote apoptosis in human kidney 293 cells (Hamada et al., 1996). In previous studies, addition of $\mathrm{Zn}-\mathrm{MT}$ was found to protect against $\mathrm{Cu}$ (II)induced DNA damage (Cai et al., 1999), whereas Cd/ Zn-MT induced plasmid DNA strand breaks (Muller et al., 1991). It is likely that MT is involved not only in metal detoxification and homeostasis, but also in scavenging free radicals during oxidative damage (Cai et al., 1999). Transcriptional induction of MT-I, and MT-II genes in the livers of $\mathrm{Cu}, \mathrm{Zn}$-superoxide dismutase knockout mice demonstrated that MTs are potent scavengers of reactive oxygen species and protect cells from oxidative stress (Ghoshal et al., 1999). Zn-MT appears to be involved in antioxidant systems, while Cu-MT isolated from the livers of $t x$ mice enhances lipid peroxidation in vitro (Stephenson et al., 1994). Depending on the heavy metals associated with it, MT appears to act as either an antioxidant or preoxidant.

It has been postulated that MTs are mainly involved in $\mathrm{Zn}$ and not $\mathrm{Cu}$ homeostasis. MT serves as means of sequestering excess zinc and providing a zinc reservoir that can be utilized when zinc is deficient (Kelly et al., 1996). MT-III, a brain specific member of the MT family (Palmiter et al., 1995), may be an important regulator of zinc in the central nervous system; its absence has been implicated in the development of Alzheimer disease (Erickson et al., 1997).

Although considerable advances have been made in studies of the physicochemical properties of MT and induction of its synthesis, comparatively little attention has been paid to its degradation. In rat pulse labeling studies in vivo, the degradation rates of MT depended upon which metals were bound to MT (Bremner et al., 1978). The half-lives of MT induced by $\mathrm{Cd}, \mathrm{Zn}$, and $\mathrm{Cu}$ were estimated to be 80,20 , and $17 \mathrm{~h}$, respectively. Several experiments showed that removal of metals from MT is the rate-limiting step in MT degradation (Feldman et al., 1978), but it is hard to estimate the accuracy of this process, because protein aggregation makes chromatographic analysis difficult. Furthermore, there has been little progress on the study of the exact location of MT degradation in cells, although it was presumed that degradation occurs mainly in the lysosome. Aggregate forms of the protein appear to be located within lysosomes (Porter et al., 1974), suggesting that Cu-MT is not readily degraded in that organelle. When MT is bound to copper, its degradation in the lysosome may not be taken place effectively due to a conformational change of MT. In our study, Cu inhibited the digestion of $\mathrm{MT}$ in vitro while $\mathrm{Zn}$ did not affect MT digestion. Improperly degraded Cu-MT could play an important role in the liver toxicity of Wilson's disease via lipid peroxidation or apoptosis.

Copper may inhibit all lysosomal enzymes, including 
the proteases that degrade MT, or copper may bind to MT and stabilize it specifically. In our experiments, we added copper to MT first in order to minimize the effect of copper on lysosomal enzymes. Our findings also imply that $\mathrm{Cu}$ cannot be effectively removed from cells by binding to MT under normal physiological conditions. We have not eliminated the possibility that there is a nonlysosomal system for Cu-MT degradation or a protein required for removal of $\mathrm{Cu}$ from $\mathrm{MT}$, which was absent from our in vitro experiments.

\section{Acknowledgement}

This work was supported by the grant of Molecular Medicine Research Group Program (98-MM-01-01-A-01) from the Ministry of Science and Technology through the biomedical research center at KAIST and in part from Ministry of Education.

\section{References}

Bremner, I., Hoekstra, W. G., Davies, N. T., Young, B. W. (1978) Effects of zinc status of rats on the synthesis and degradation of copper-induced metallothionein. Biochem. J. 174: 883-92

Cabre, M., Ferre, N., Folch, J., Paternain, J. L., Hernandez, M., del Castillo, D., Joven, J. and Camps, J. (1999). Inhibition of hepatic cell nuclear DNA fragmentation by zinc in carbon tetrachloride-treated rats. J. Hepatol. 31: 228-234

Cai, L., Satoh, M., Tohyama, C. and Cherian, M. G. (1999) Metallothionein in radiation exposure: its induction and protective role. Toxicology 132: 85-98

Danks, D. (1995) in The Metabolic and Molecular Bases of Inherited Disease (Scriver, C. S., Beaudet, A. L., Sly, W. S. and Valle, D., Eds), pp. 2230, McGraw-Hill, New York

Deng, D. X., Cai, L., Chakrabarti, S. and Cherian, M. G. (1999). Increased radiation-induced apoptosis in mouse thymus in the absence of metallothionein. Toxicology 134: 39-49

Erickson, J. C., Hollopeter, G., Thomas, S. A., Froelick, G. J. and Palmiter, R. D. (1997) Disruption of the metallothionein-III gene in mice: analysis of brain zinc, behavior, and neuron vulnerability to metals, aging, and seizures. J. Neurosci. 17: 1271-1281

Feldman, S. L., Failla, M. L. and Cousins, R. J. (1978) Degradation of rat liver metallothioneins in vitro. Biochmica. Biophysica. Acta. 544: 638-646

Ghoshal, K., Majumder, S., Li, Z., Bray, T. M. and Jacob, S. T. (1999) Transcriptional induction of metallothionein-I and -II genes in the livers of $\mathrm{Cu}, \mathrm{Zn}$-superoxide dismutase knockout mice. Biochem. Biophy. Res. Commun. 264: 735-742

Hahn, S. H., Brantly, M. B., Oliver, C., Adamson, M., Kaler, S. and Gahl, W. A. (1994). Metallothionein synthesis and degradation in Indian childhood cirrhosis fibroblasts. Pediat. Res. 35:
197-204

Hahn, S. H., Tanner, M. S., Danks, D. M. and Gahl, W. A. (1995) Normal metallothionein synthesis in fibroblasts obtained from children with indian childhood cirrhosis or copper associated childhood cirrhosis. Bio. Mol. Med. 54: 142-145

Hamada, T., Sasaguri, T., Tanimoto, A., Arima, N., shimajiri, S., Abe, T. and Sasaguri, Y. (1996) Apoptosis of human kidney 293 cells is promoted by polymerized cadmium-metallothionein. Biochem. Biophys. Res. Commun. 219: 829-834

Hamer, D. H. (1985). Metallothionein. Annu. Rev. Biochem. 55: $913-51$

Kawanishi, S. and Yamamoto, K. (1991). Mechanism of sitespecific DNA damage induced by methylhydrazines in the presence of copper (II) or manganese (III). Biochemistry 30: 3069-3075

Kelly, E. J., Quaife, C. J., Froelick, G. J. and Palmiter, R. D. (1996) Metallothionein I and II protect against zinc deficiency and zinc toxicity in mice. J. Nutr. 126: 1782-1790

Klaassen, C. D. and Liu, J. (1998) Metallothionein transgenic and knock-out mouse models in the study of cadmium toxicity. J. Toxicol. Sci. Suppl. 2: 97-102

Kondo, Y., Rusnak, J. M., Hoyt, D. G., Settineri, C. E., Pitt, B. R. and Lazo, J. S. (1997) Enhanced apoptosis in metallothionein null cells. Mol. Pharmacol. 52: 195-201

Liu, J., Liu, Y., Michalska, A. E., Choo, K. H. and Klaassen, C. D. (1996) Distribution and retention of cadmium in metallothionein I and II null mice. Toxicol Appl Phamarcol 136: 260-268

Liu, J., Liu, Y., Michalska, A. E., Choo, K. H. and Klaassen, C. D. (1996) Metallothionein plays less of a protective role in cadmium-metallothionein-induced nephrotoxicity than in cadmium chloride-induced hepatoxicity. J. Pharmacol. Exp. Ther. 276: $1216-1223$

Marshall, L. E., Graham, D. R., Reich, K. A. and Sigman, D. S. (1981) Cleavage of deoxyfibronucleic acid by the 1:10phenanthroline-cuprous complex: Hydrogen peroxide requirement and primary and secondary structure specificity. Biochemistry 20: 244-250

Mehra, R. K. and Bremner, I. (1985) Studies on the metabolism of rat liver copper-metallothionein. Biochem. J. 227: 903-980

Michalska, A. E., Choo, K. H. (1993) Targeting and germ-line transmission of a null mutation at the metallothionein I and II loci in mouse. Proc. Natl. Acad. Sci. U S A. 90: 8088-8092

Muller, T., Schuckelt, R. and Jaenicke, L. (1991) Cadmium/ zinc-metallothionein induces DNA strand breaks in vitro. Arch. Toxicol. 65: 20-26

Palmiter, R. D., Findley, S. D., Wjitmore, T. E. and Durnam, D. M. (1992) MT-III, a brain specific member of the metallothionein gene family. Proc. Natl. Acad. Sci. USA. 89: 6333-6337

Porter, H. (1974) The particulate half-cystine-rich copper protein of newborn liver. Relationship to metallothionein and subcellular localization in non-mitochondrial particles possibly representing heavy lysosomes. Biochem Biophys Res Commun 56: $661-668$ 
Que, B. G., Downey, K. M. and So, A. G. (1980) Degradation of deoxyribonucleic acid by a 1:10-phenanthroline-copper complex: The role of hydroxyl radicals. Biochemistry 19: 59875991

Ragab, H., Beck, C., Dillard, C. and Tappel, A. L. (1967) Preparation of rat liver lysosomes. Biochim. Biophys. Acta. 148: 501-505

Stephenson, G. F., Chan, H. M. and Chrian, M. G. (1994) Copper-metallothionein from the toxic milk mutant mouse enhances lipid peroxidation initiated by an organic hydroperoxide. Toxicol. Appl. Pharmacol. 125: 90-96

Tsangaris, G. T. and Tzortzatou-Stathopoulou, F. (1998) Metallothionein expression prevents apoptosis: a study with antisense phosphorothioate oligodeoxynucleotides ina human $\mathrm{T}$ cell line. Anticancer. Res. 18: 2423-2433

Xi Deng, D., Ono, S., Koropatnick, J. and Cherian, M. G. (1998) Metallothionein and apoptosis in the toxic milk mutant mouse. Lab. Invest. 78: 175-183 